\title{
Evidence Based Physiotherapy Guideline for Conservative Management of Ankle Sprain
}

\author{
K M Amran Hossain ${ }^{1}$, Md Obaidul Haque ${ }^{1 *}$, Mohammad Habibur Rahman $^{2}$ and Mohammad Anwar \\ Hossain $^{3}$ \\ ${ }^{1}$ Bangladesh Health Professions Institute, Bangladesh \\ ${ }^{2}$ Bangladesh Open University, Bangladesh
}

${ }^{3}$ Centre for the Rehabilitation of the Paralysed (CRP), Bangladesh

*Corresponding author: Md Obaidul, Haque, Professor and Head of Physiotherapy Department, Vice-Principal, Bangladesh

Health Professions Institute (BHPI), Bangladesh

\begin{tabular}{|c|c|}
\hline ARTICLE INFO & ABSTRACT \\
\hline Received: 閩 November 20, 2019 & Citation: K M Amran Hossain, Md Obaidul Haque, Mohammad Habibur Rahman, \\
\hline Published: 慧 December 02, 2019 & $\begin{array}{l}\text { Mohammad Anwar Hossain. Evidence Based Physiotherapy Guideline for Conservative } \\
\text { Management of Ankle Sprain. Biomed J Sci \& Tech Res 23(2)-2019. BJSTR. MS.ID.003885. }\end{array}$ \\
\hline
\end{tabular}

\section{Mini Review}

Ankle sprain is considered to be a commonest sports injury globally [1]. Sprain to the lateral ligaments of ankle in inversion mechanism consists more than $85 \%$ of ankle sprains [2]. Among the lateral ligaments the anterior talofibular ligament (ATFL) is the weakest one among them involving in all cases of lateral ligament sprain, hence calcaneofibular ligament (CFL) involves in more than one third case, and posterior talofibular ligament (PFL) involves in less than $10 \%$ of cases [3]. Meta-analysis found [4] ankle sprain constitutes 13.6 of prevalence in female athlete and 6.94 in male athlete per 1000 exposure and football, cricket, rugby, basketball, tennis, wrestling, skiing, ice hockey, parachuting, rock climbing, and tracking are the premier sports to incident ankle sprain. Ankle sprain is also evident to be one of the commonest injuries around ankle in non-sports persons [5]. A study estimated 18\% of the female athletes trained at BKSP has ankle sprain in Bangladesh [6]. Physiotherapy is one of the primer contributors to conservative management approach for ankle sprain [7] hence there are recommendations to establish a comprehensive physical therapy guideline for ankle sprain in customized to region and cultural context.

\section{Methodology}

Authors searched BHPI library database which omit links with BRACKEN Health Sciences Library, Queen's University Canada and the Bangladesh Academy of Sciences (INASP), HINARI Summon,
PEDro, Pubmed, CINHAL and Cochrane database with the key words "Ankle sprain AND Physical Therapy", Lateral Ligament sprain AND Physiotherapy", "Guideline AND Ankle Sprain". 72 related articles found within the time range 2010-2019. Among them 43 publications were Scopus indexed journals. The interventions of the guideline was formulated by synopsis of systematic reviews following PRISMA and RCT's having PEDro score equal or more than 5 out of 10 . After the preparation of guideline, authors discussed with senior clinicians having more than 10 years' experience in practicing physiotherapy in Bangladesh to re-check the applicability of the guideline.

\section{Diagnosis of Ankle Sprain}

Diagnosis is considered to be the first attempt in managing ankle sprain. Polzer and colleagues reviewed the diagnosis of lateral ankle sprain that is comprehensive to Magnetic resonance imaging findings that nested as sign of inflammation, soft tissue tension test, activity limitations and radiographic findings [8]. The positive inflammatory sign with negative tension test categorized as grade I lesion and interpreted as incomplete tear of ATFL. Subsequently inflammation with positive ADT interpreted as complete tear of ATFL and incomplete tear of CFL, inflammation with positive ADT and taller test is considered as complete (G-III) tear. The diagnostic algorithm (Figure 1) of ankle sprain cases followed by acute onset plays a vital role for appropriate management of Ankle Sprain cases. 


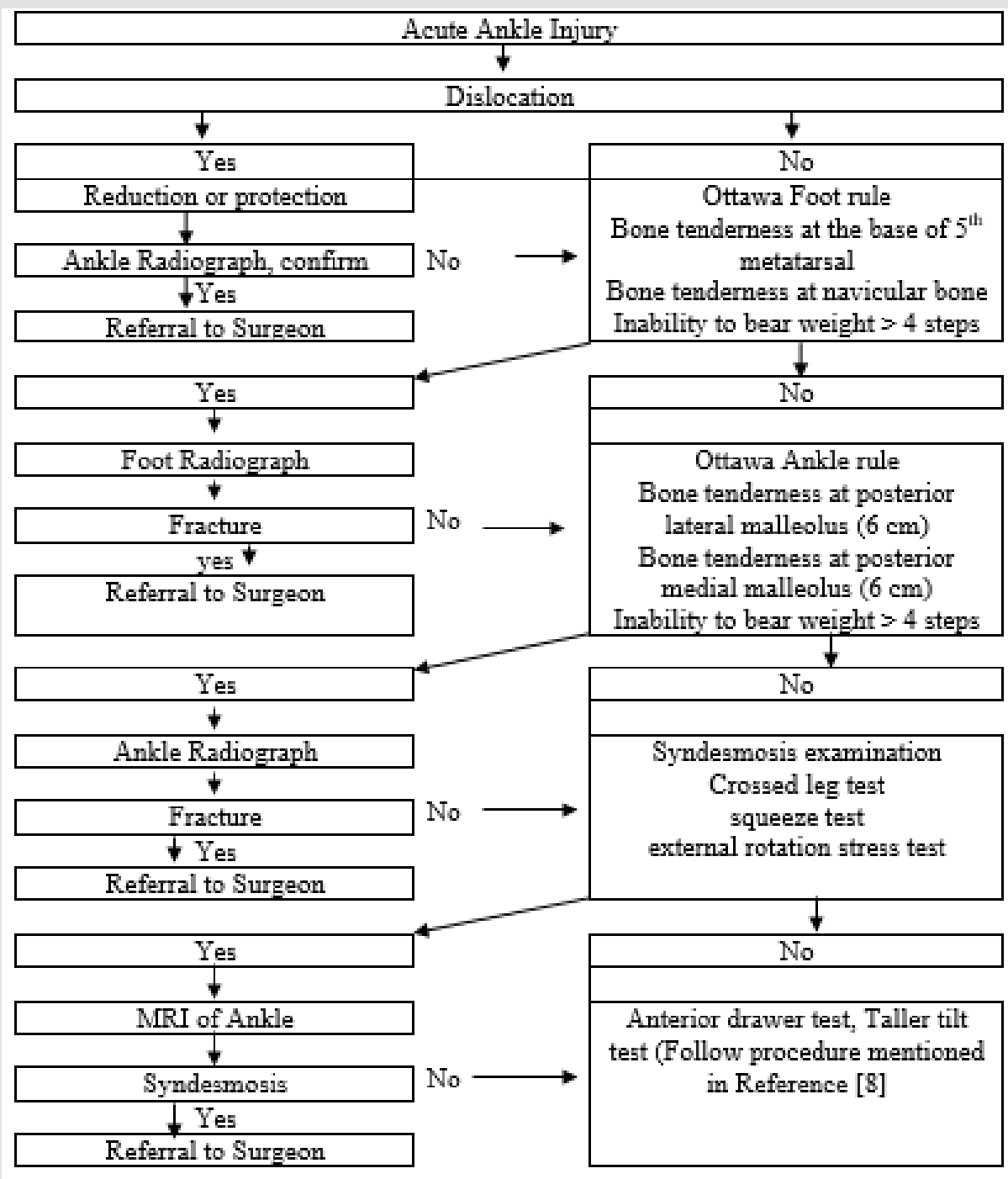

Figure 1: Diagnostic algorithm for ankle sprain.

\section{Physiotherapy Management Protocol}

Brison and colleagues [9] explored a structured scheme for managing ankle sprain cases based on duration and impairments. The protocol designed to be implemented from 72 hours to 6 weeks after injury. The principle of the protocol advances with the remission of inflammatory sign; improve joint play, promotion of strength and regaining proprioception.

\section{Acute Stage (0-7 days)}

Ice application is a gold standard management protocol in all grades of acute ankle sprain [10], recent studies suggests the procedure where ankle is submerged in a cold immersion cylinder in 50-60 degree Fahrenheit for 20 minutes is the superior approach to relieve pain and swelling 3-5 days prior to injury. Some studies suggest ice compression by crushed ice over anterolateral aspect in elevated limb above heart level for 20 minutes twice a day for 7 days has significant effect on pain and swelling in lateral ankle sprain cases. Also, elevation of limbs was noted to put on $25 \%$ of total day time for 7 days. Moreover, Protection can be performed by using bandage and tapes [11].

\section{Sub-Acute Stage (7 Days Onwards)}

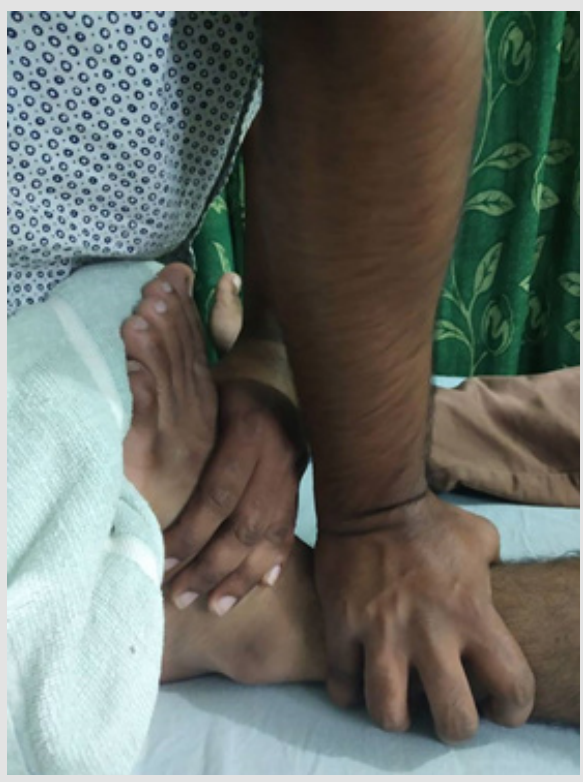

Figure 2: AP mobilization of the talus. 
In this stage antero-posterior glide on the talus with RICE protocol can be applied. The mobilization is performed in supine lying of the patient and the ankle positioned over the edge of the plinth. The proximal hand of the physiotherapist (hand marked) stabilized the distal tibia and fibula while the distal (right) hand mobilized the talus with posteriorly directed oscillations (Figure 2). The mobilizations can be performed in Maitland concept 60 oscillations in 60 seconds, two set of exercise with 10 seconds rest for two weeks in alternative days. Ice is applied after the mobilizations. After two weeks RCT's [12] found positive impact in dorsiflexion range and gait parameter in subacute stage of ankle sprain.

\section{Chronic Stage (21 Days Onwards)}

In chronic stage, Neuromuscular training alone or with proprioceptive training found to be effective to improve stability Table 1: Neuromuscular Training (with patients permission). and functional outcome in ankle sprain in a meta-analysis [13]. The customized neuromuscular exercise (Table 1 ) is recommended to apply for the rehabilitation stage of managing Ankle sprain for one to three sessions a week, with a maximum duration of $30 \mathrm{~min}$ per session for 8 weeks. Also, proprioceptive exercises alone (Table 2) found effective measure to regain ankle stability and improving functions in addition to conventional measures in ankle sprain cases [14]. Vasconcelos and colleagues [15] suggested proprioceptive exercises along with balance exercise increases dynamic neuromuscular control, postural sway, and the joint position sense in athletes. The proprioceptive exercises are recommended to perform as 6 weeks of balance training, 20-minute session, 5 times a week to improve ankle instability. Strengthening program of plantar flexion, dorsiflexion, inversion, and eversion motions plays an important role in stabilizing ankle in rehabilitation stage.

A) One legged knee flexion on even surface with eyes open and close, and on a balance board on standing position.

B) Toe stand with support to hand and without support to hand
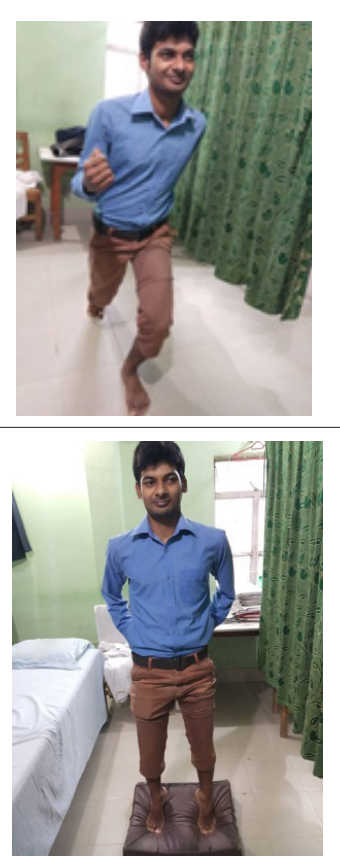

C) One legged stance on even surface with eyes open and close, and on a balance board on standing position.

D) Runners pose on even surface with eyes open and close, and on a balance board on standing position.
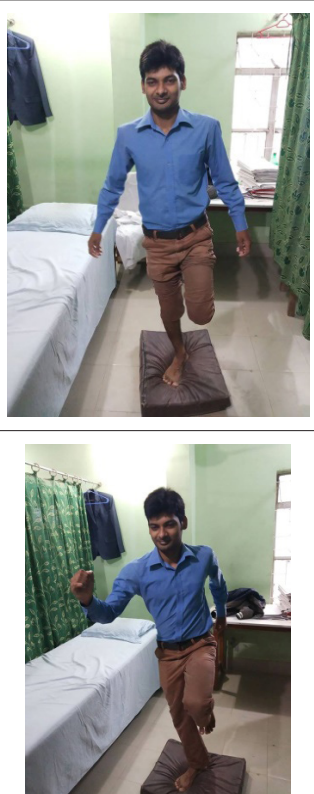


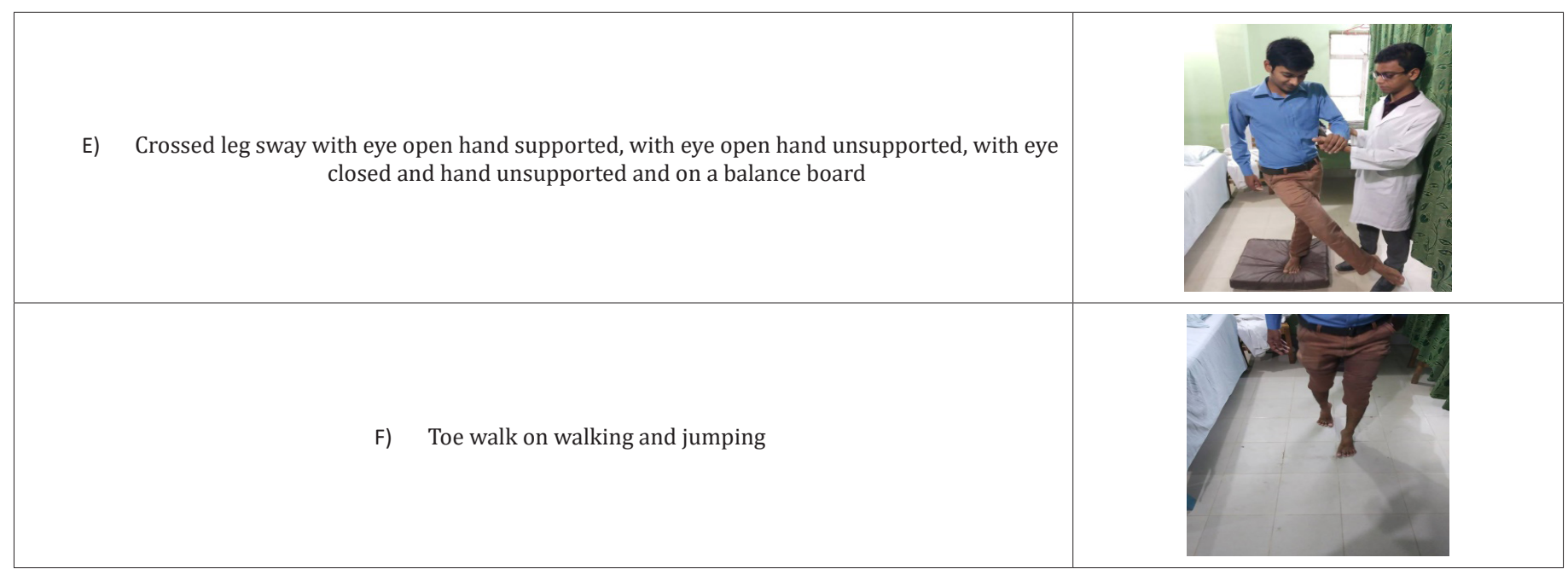

Table 2: Proprioceptive training (with patient permission).

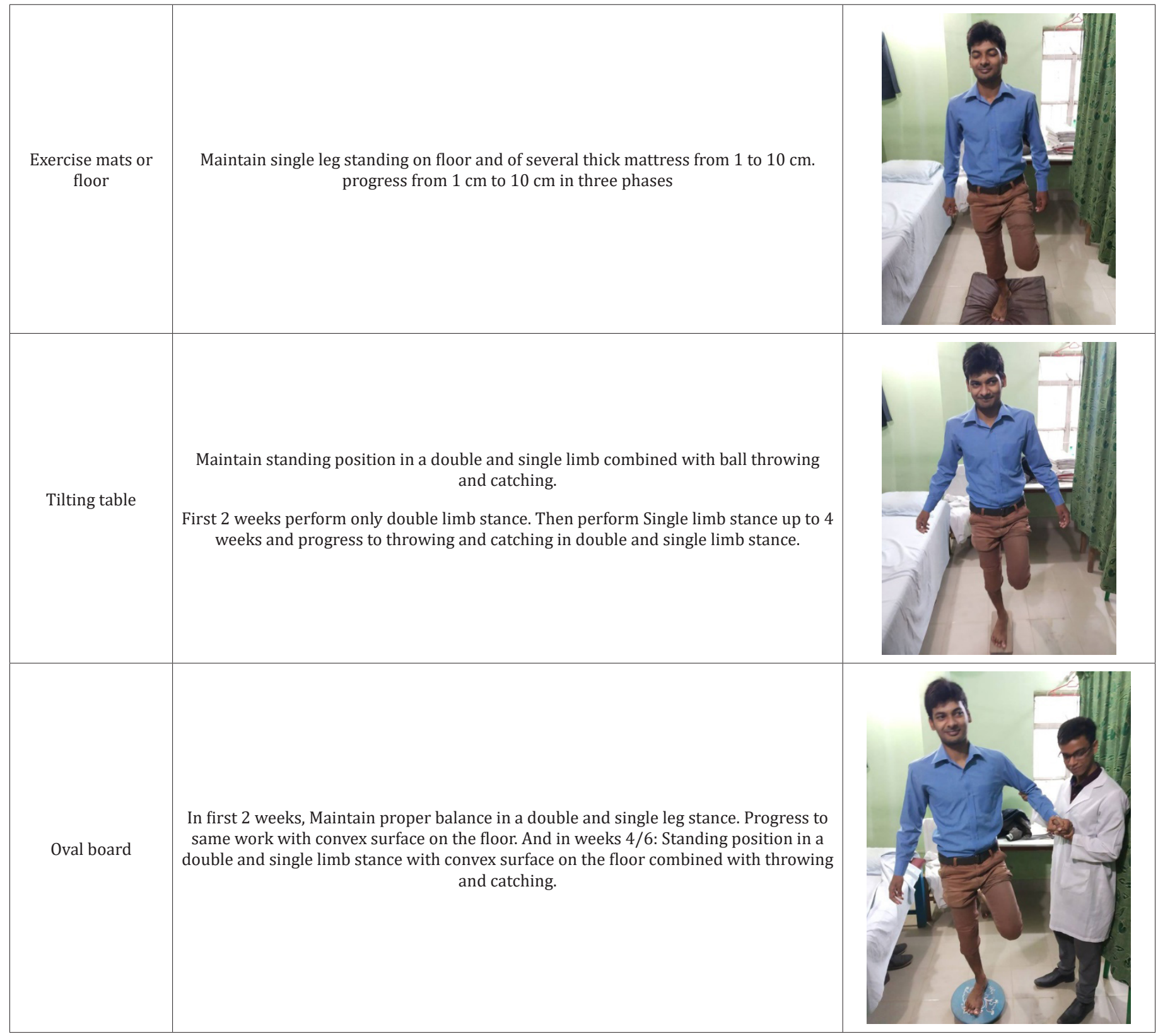




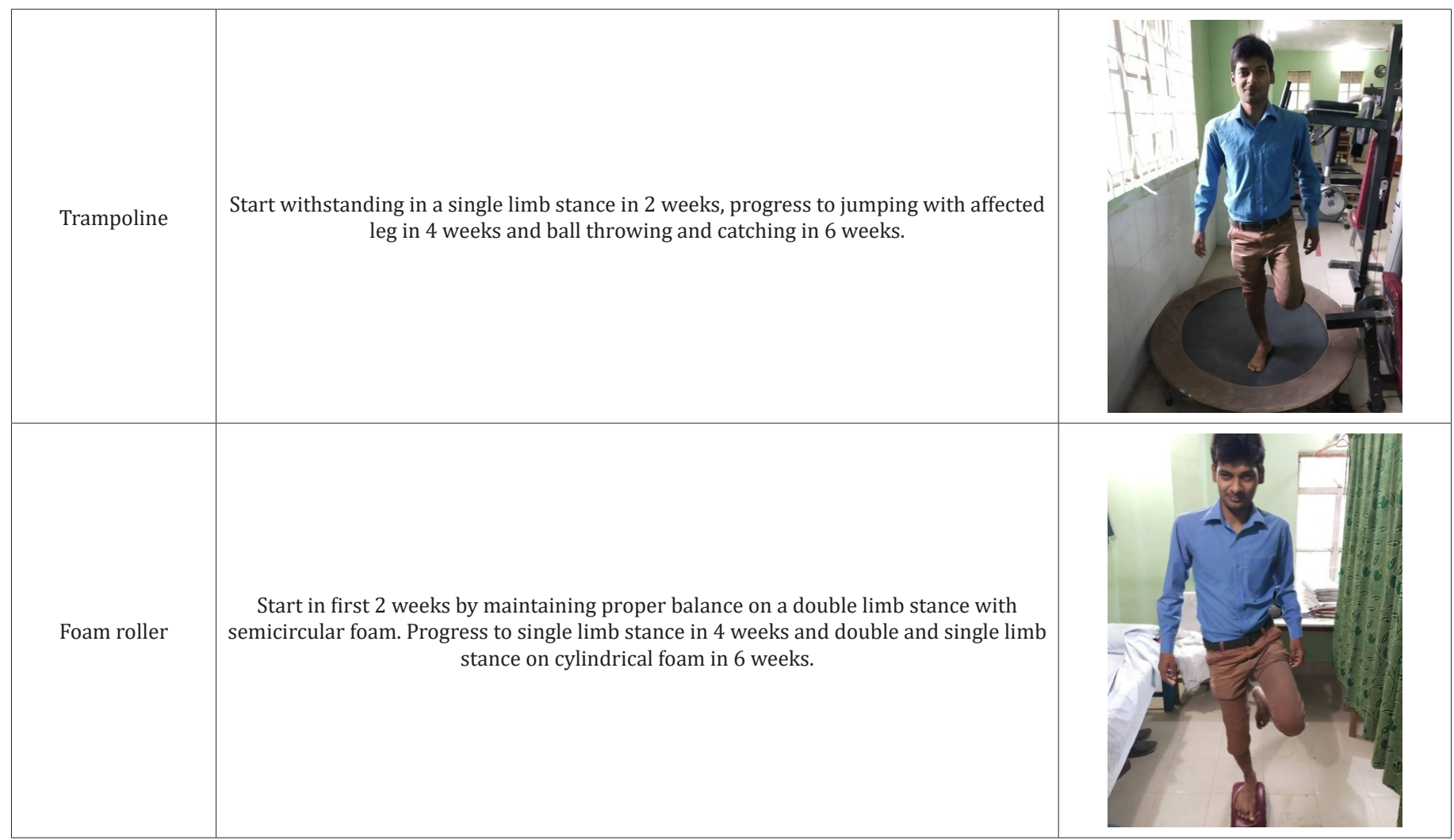

Studies suggest 6 weeks individualized concentric strength training with balance training improves stability and prevent recurrences in ankle sprain [15]. Home exercises play a vital role in ankle sprain cases. The home exercise designed as per capability and generalized skills of patients or caregiver is an integral approach to conservative management of ankle sprain [16]. Other interventions have been mentioned as Laser therapy, ultrasound, hyperbaric oxygen therapy, platelet rich plasma, hyaluronic acid [17] and these treatments should not be considered as part of the standard regime in treating acute ankle injuries. Return to work or sports are premier concern in rehabilitation. Evidence [18] suggests, in case of distortion injury it takes 2 weeks to return to light work and 3-4 weeks for full restoration to work. And in case of partial or total rupture of ligaments, it takes 3-6 weeks to introduce light work and 6-8 weeks for full restoration of work. The full workload considered as full sitting activities lifting less than $10 \mathrm{~kg}$ weight. Although, this can vary according to extend and management of injury.

\section{Conclusion}

Ankle sprain is one of the prime causes of instability of the ankle leading to functional impairments and decreased participation to sports and work. Conservative management found to be a gold standard treatment option that depends upon the diagnosis and assessing extends of injury. Physiotherapy plays an important role in relieving inflammatory sign, improving function, stability, proprioception and prevention of recurrences.

\section{Acknowledgement}

BHPI MPT faculties for their contribution in searching and appraising literatures and evidences.

\section{Conflict of Interest}

No conflict of interest.

\section{References}

1. Attenborough AS, Sinclair PJ, Sharp T, Greene A, Stuelcken M, et al (2017) The identification of risk factors for ankle sprains sustained during netball participation. Physical therapy in sport 23: 31-36.

2. Ferran NA, Maffulli N (2006) Epidemiology of sprains of the lateral ankle ligament complex. Foot and ankle clinics 11(3): 659-662.

3. Bäcker HC, Krause F, Attinger MC (2017) Treatment of chronic lateral ankle instability-a review. JSM foot and ankle 25: 2(1).

4. Doherty C, Bleakley C, Delahunt E, Holden S (2017) Treatment and prevention of acute and recurrent ankle sprain: an overview of systematic reviews with meta-analysis. Br J Sports Med 51(2): 113-125.

5. Dearden PM, Reeve WJ, Sharpe IT (2018) Management of acute ankle ligament injuries. Orthopaedics and Trauma 32(6): 394-400.

6. Bristi SN, Prevalence of sports injuries among female athletes (Doctoral dissertation, Bangladesh Health Professions Institute, Faculty of Medicine, the University of Dhaka, Bangladesh).

7. Brison RJ, Day AG, Pelland L, Pickett W, Johnson AP, et al. (2016) Effect of early supervised physiotherapy on recovery from acute ankle sprain: randomised controlled trial. Bmj 355: i5650.

8. Polzer H, Kanz KG, Prall WC, Haasters F, Ockert B, et al. (2012) Diagnosis and treatment of acute ankle injuries: development of an evidencebased algorithm. Orthopedic reviews 4(1).

9. Brison RJ, Day AG, Pelland L, Pickett W, Johnson AP, et al. (2016) Effect of early supervised physiotherapy on recovery from acute ankle sprain: randomised controlled trial. Bmj 355: i5650.

10. Chen ET, McInnis KC, Borg Stein J (2019) Ankle Sprains: Evaluation, Rehabilitation, and Prevention. Current Sports Medicine Reports 18(6): 217-223.

11. Acar YA, Yilmaz BK, Karadeniz M, Cevik E, Uzun O, et al. (2015) Kinesiotaping vs elastic bandage in acute ankle sprains in emergency 
department: A randomized, controlled, clinical trial. Gulhane Medical Journal 57(1): 44-48.

12. Green T, Refshauge K, Crosbie J, Adams R (2001) A randomized controlled trial of a passive accessory joint mobilization on acute ankle inversion sprains. Physical therapy 81(4): 984-994.

13. Doherty C, Bleakley C, Delahunt E, Holden S (2017) Treatment and prevention of acute and recurrent ankle sprain: an overview of systematic reviews with meta-analysis. Br J Sports Med 51(2): 113-125.

14. Doherty C, Bleakley C, Delahunt E, Holden S (2017) Treatment and prevention of acute and recurrent ankle sprain: an overview of systematic reviews with meta-analysis. Br J Sports Med 51(2): 113-125.

15. Hall EA, Chomistek AK, Kingma JJ, Docherty CL (2018) Balance-and Strength-Training Protocols to Improve Chronic Ankle Instability

ISSN: 2574-1241

DOI: 10.26717/BJSTR.2019.23.003885

Md Obaidul Haque. Biomed J Sci \& Tech Res

(C) This work is licensed under Creative

Submission Link: https://biomedres.us/submit-manuscript.php
Deficits, Part II: Assessing Patient-Reported Outcome Measures. Journal of athletic training 53(6): 578-583.

16. Feger MA, Herb CC, Fraser JJ, Glaviano N, Hertel J (2015) Supervised rehabilitation versus home exercise in the treatment of acute ankle sprains: a systematic review. Clinics in sports medicine 34(2): 329-346.

17. Vuurberg G, Hoorntje A, Wink LM, Van Der Doelen BF, Van Den Bekerom MP, et al. (2018) Diagnosis, treatment and prevention of ankle sprains: update of an evidence-based clinical guideline. Br J Sports Med 52(15): 956.

18. Tassignon B, Verschueren J, Delahunt E, Smith M, Vicenzino B, et al. (2019) Criteria-based return to sport decision-making following lateral ankle sprain injury: a systematic review and narrative synthesis. Sports Medicine 49(4): 601-619.

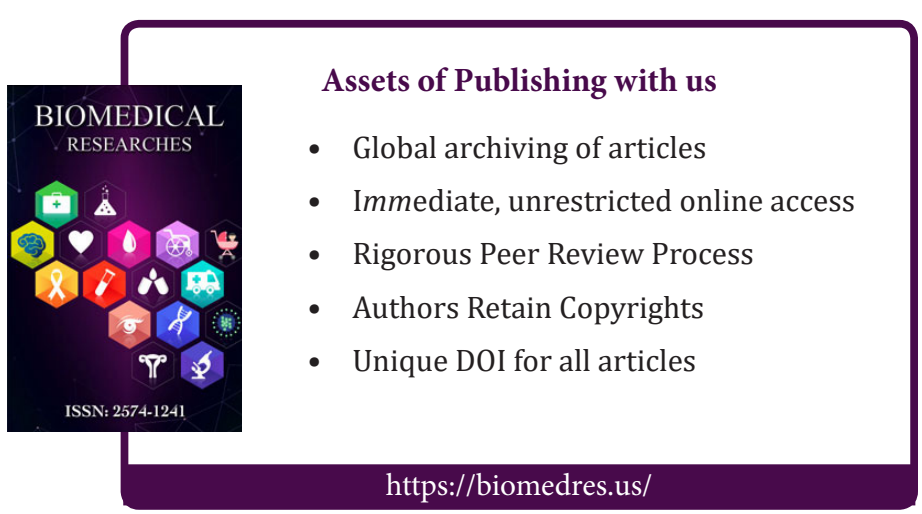

